\title{
O vermelho na construção da imagem de Dilma Rousseff
}

The red in the construction of Dilma Roussef's image

El rojo en la construcción de la imagen de Dilma Roussef

Jessica de Campos - Uniso | Sorocaba | SP | Brasil | e-mail: jeehcriistina@gmail.com | Orcid: https://orcid.org/0000-0001-8658-8818

Luciana Souza - Uniso | Sorocaba | SP | Brasil | e-mail: Luciana.souza@prof.uniso.br | Orcid: https://orcid.org/0000-0002-1995-8791

Resumo: A produção de sentidos da cor vermelha das vestes da ex-presidente Dilma Rousseff, no período que precede seu primeiro mandato até seu impeachment, é foco neste artigo. O que se propõe é verificar como a presença ou ausência da cor vermelha de suas vestimentas, em seus aspectos qualitativo, existencial e simbólico, atuam na construção da imagem da ex-presidente. Na esteira do vermelho, fotos de Dilma da plataforma digital do jornal Folha de S.Paulo são analisadas à luz da semiótica peirciana, levando em conta o contexto de sua trajetória política. O resultado a que chegamos, na trilha do vermelho, permitiu-nos vislumbrar a conveniência do uso desta cor como índice do pertencimento ou do afastamento do Partido dos Trabalhadores.

Palavras-chave: Comunicação. Produção de sentidos. Vermelho. Dilma Roussef.

Abstract: The production of red-colored senses in the clothes of former President Dilma Rousseff, in the period preceding her first term until her impeachment, is the focus of this article. What we propose is to verify how the presence or absence of the red color of her clothes, in their qualitative, existential and symbolic aspects, act in the construction of the former president's image. Concerning the red, photos of Dilma from the digital platform of the newspaper Folha de S.Paulo are analyzed in the light of the Peircean semiotics, taking into account the context of her political trajectory. The result we reached, on the red trail, allowed us to glimpse the convenience of using this color as an index of belonging or withdrawing from the Workers' Party.

Keywords: Communication. Production of senses. Red. Dilma Roussef.

Resumen: La producción de los sentidos de color rojo en la ropa de la ex presidenta Dilma Rousseff, en el período anterior a su primer mandato hasta su juicio político, es el tema central de este artículo. Lo que proponemos es verificar cómo la presencia o ausencia del color rojo de su ropa, en sus aspectos cualitativos, existenciales y simbólicos, actúan en la construcción de la imagen del ex presidente. A raíz del rojo, las fotos de Dilma de la plataforma digital del periódico Folha de S. Paulo se analizan a la luz de la semiótica de Peirce, teniendo en cuenta el contexto de su trayectoria política. El resultado que alcanzamos, en el camino rojo, nos permitió vislumbrar la conveniencia de usar este color como un índice de pertenencia o retiro del Partido de los Trabajadores.

Palabras clave: Comunicación. Producción de significados. Rojo. Dilma Roussef.

- Recebido em: 02 abr. 2020 - Aprovado em: 13 abr. 2020 - e-ISSN: 2177-5788

DOI: https://doi.org/10.22484/2177-5788.2020v46n1p127-142

Copyright @ 2020. Conteúdo de acesso aberto, distribuído sob os termos da Licença Internacional da Creative Commons-CC BY-NC-SA - Atribuição Não Comercial Permite distribuição e reprodução, desde que atribuam os devidos créditos à publicação, ao autor(es) e que licenciem as novas criações sob termos idênticos. 


\section{Introdução}

A moda entendida como comunicação abriga o objeto desse artigo: a produção de sentidos da cor vermelha das vestes da presidente Dilma Rousseff, nas fotografias jornalísticas da plataforma digital da Folha de S.Paulo.

Este artigo dialoga com outras pesquisas que também tiveram objeto semelhante. A dissertação "A roupa da Presidente: uma análise de comunicação pelas vestes", de Oliveira (2015), traz à tona a roupa como reflexo da vida e, sua escolha, volta-se, sobretudo, para a ritualização e representação da vida cotidiana.

A dissertação de Cunha (2014), "Dilma Rousseff da Ditadura Militar ao Facebook - a construção da imagem do indivíduo na política", propõese, através do fotojornalismo, a aproximar períodos históricos e identificálos, para assim compreender o percurso da construção da imagem de Dilma Rousseff e conseguir contextualizar historicamente em conjunto com as publicações de uma página do Facebook.

Também o artigo de Queiroz e Martins (2011) aborda de que forma o tema "moda" ganhou espaço nos editoriais de política que cobriram as eleições presidenciais no Brasil em 2010. Os autores enfatizam o fato de que uma candidata mulher ampliou a área de interesse do jornalismo em relação a sua vestimenta e questiona se a moda teve igualmente importância ao longo da campanha, na medida em que o visual da candidata foi se alterando. Aprofundar esta questão levantada neste artigo, buscando relacionar as vestimentas da Presidente a momentos da sua carreira política pareceu-nos importante para verificar como a imagem de Dilma Rousseff foi sendo construída na sua trajetória política.

Para fundamentarmos a moda como forma de comunicação valemonos de Barnard (2003), para quem as vestes são utilizadas para sintetizar ideias, conceitos, desejos e vontades. A roupa comunica e as escolhas que fazemos são representativas da ritualização do nosso cotidiano. Desta forma, podemos utilizar a roupa para veicular mensagem com funções REU, Sorocaba, SP, v. 46, n. 1, p. 127-142, jun. 2020 
distintas como: informativa, expressiva, normativa e de interação social e, mais do que isso, revelar sentidos.

Para a análise de como a cor vermelha nas vestes da ex-presidente produz sentidos será utilizada a semiótica peirciana que nos atenderá ancorada por outros conhecimentos, tais como a psicologia das cores por Heller (2013), e o entendimento da simbologia das cores inscrita no dicionário da moda, de Sabino (2007).

Com base nesses autores, buscamos mostrar a cor na vestimenta na esfera da comunicação, no seu caráter de instrumento na interação da expresidente com o coletivo em determinados momentos de sua trajetória política. O primeiro deles está representado na foto de campanha da primeira eleição (2010), em que aparece junto com o ex-presidente Lula. Tal escolha se deve ao fato de ser uma de suas primeiras aparições como candidata à presidência. O segundo momento foi sua posse como presidente eleita (2010): a primeira mulher brasileira a se estabelecer como chefe de governo.

O terceiro momento diz respeito a alguns eventos que marcaram sua ascensão durante o primeiro mandato, de 2010 a 2014. Para tanto, apresentamos um painel com quatro imagens que retratam esse período.

O quarto momento mostra o que seria o seu declínio, também composto por um painel contendo quatro imagens da Dilma em alguns dos seus últimos momentos como presidente (2015-2016). A cassação de seu mandato, é representada no quinto momento.

Definidos os flashes da carreira da presidente Dilma que serão nosso corpus, passemos à apresentação do instrumental metodológico e, a seguir, às análises. 


\section{A semiótica peirciana: fundamentos para a análise}

Para deslindar os sentidos que a cor vermelha assume, de acordo com os fatos vivenciados pela presidente, a semiótica peirciana foi a escolhida por permitir que adentrássemos o espectro desta cor, ora como qualidade, como existente e, finalmente, como lei.

Toda a arquitetura da teoria de Peirce, da qual a semiótica ocupa o centro, se alicerça em três categorias fenomenológicas. Tendo a fenomenologia como porta de entrada de sua teoria, essa quase-ciência "tem por função apresentar as categorias formais e universais dos modos como os fenômenos são apreendidos pela mente" (SANTAELLA, 2005, p. 7). Depois de muito observar os fenômenos, ou tudo aquilo que aparece à mente, Peirce concluiu que há três elementos formais universais denominados: primeiridade, secundidade e terceiridade.

A primeiridade está relacionada ao acaso, ao sentimento, à originalidade, à possibilidade, à liberdade. Esses atributos possibilitam o estado de contemplação, de encantamento.

A secundidade está ligada às ideias de ação e reação, de dependência, determinação, conflito, é a categoria da comparação, do fato, da realidade, do aqui e agora. Já a terceiridade está ligada à mediação, à memória, à representação, ao pensamento e à interpretação dos signos. A terceiridade é o locus onde se manifesta o signo, "visto que o signo é um primeiro (algo que se apresenta à mente), ligando um segundo (aquilo que o signo indica, se refere ou apresenta) a um terceiro (o efeito que o signo irá provocar em um possível intérprete)" (SANTAELLA, 2005, p. 7).

A partir dessas categorias, respectivamente, podemos analisar os signos na sua relação com ele mesmo (significação), na relação com o objeto (objetivação) e na relação com o interpretante (interpretação). Na relação consigo mesmo, os signos se apresentam nos seus fundamentos de simples qualidades (qualissignos), no seu aspecto de um existente singular (sinsignos) e no seu aspecto de lei, convenção (legissignos). 
Na relação com o objeto, os signos se classificam como ícones, apresentam semelhança com o objeto que representam; índices, são parte do objeto a que se referem e símbolos, signos que representam seus objetos mediante uma convenção.

Na relação com o interpretante, ou seja, na maneira como os signos produzem sentidos alicerçados nas três categorias, se o signo tem a qualidade como dominante, é a emoção que virá à tona. Se o signo tem como marca o fato de ser existente, provocará ação/reação, constatação. Se o signo é de lei, produzirá interpretantes mais desenvolvidos, capazes de generalizar, argumentar, traduzir reflexões embasadas na lógica.

O vermelho é cor $e$, como tal, produz sentimentos que podem vir apenas da sua qualidade de cor (a vermelhidão de uma tela que nos invade o olhar e favorece a pura contemplação). Sob esse modo de "aparecer", ele será um qualissigno e poderá provocar sentimentos, emoção. Pode ser um existente singular (sinsigno) e, nesse caso, ele estará incorporado em alguma forma: no caso específico deste artigo, as vestimentas da presidente Dilma Rousseff. Finalmente, se a lei for o fundamento que o leva a produzir sentidos, então ele será um legissigno e estará prenhe de aspectos culturais, de símbolos, o que o fará representar ideias, pensamentos, convenções, como a cor/símbolo do Partido dos Trabalhadores (PT). Como legissigno, o vermelho está ancorado na História e na cultura.

\section{A cor vermelha como qualidade}

A cor, segundo Dondis (2007), está impregnada de informação e é uma das mais penetrantes experiências visuais que temos todos em comum. Por essa razão, é fundamental para comunicadores visuais.

Para esta autora, as cores têm significados associativos compartilhados no ambiente natural, a cor do céu, terra, mar, relva e de um número sem fim desses elementos. A todos eles associamos um significado, mas há aqueles sentidos que ultrapassam esse conhecimento 
relacionado ao ambiente e ganham sentidos vincados na cultura. Dondis (2007, p. 64) exemplifica com o vermelho, senão vejamos:

\begin{abstract}
O vermelho que associamos à raiva passou também para 'a bandeira (ou capa) vermelha que se agita diante do touro. O vermelho pouco significa para o touro, que não tem sensibilidade para a cor e só é sensível ao movimento da bandeira ou capa. Vermelho significa perigo, amor, calor e vida, e talvez mais uma centena de coisas. Cada uma das cores também tem inúmeros significados associativos e simbólicos.
\end{abstract}

A cor tem três dimensões que podem ser definidas e medidas. A primeira é a matiz, a cor em si. Cor, então, como pura qualidade ou qualissigno. Existem três matizes primárias: vermelho, amarelo e azul. Cada uma delas tem qualidades fundamentais: o amarelo é a cor mais próxima da luz e do calor; o vermelho é a mais ativa e emocional; o azul é passivo e suave.

Centrando-nos no vermelho, ainda a partir de Dondis (2007), temos que esta cor tende a se expandir. Quando associada através de misturas, são obtidos novos significados: se é misturado ao azul, o significado provocador do vermelho é amenizado, mas intensificado ao misturar-se com o amarelo.

A saturação é a segunda dimensão da cor e está ligada à pureza relativa da cor. Saturada é a cor simples, quase primitiva. Para Dondis (2007, p. 66), a saturação "é explicita e unívoca; compõe-se dos matizes primários e secundários" e mais:

\footnotetext{
Quanto mais intensa ou saturada for a coloração de um objeto ou acontecimento visual, mais carregado estará de expressão ou emoção. Os resultados informacionais, na opção por uma cor saturada ou neutralizada, fundamentam a escolha em termos de intenção.
}

A terceira dimensão da cor é a acromática, é o brilho relativo, do claro ao escuro, das gradações de tom e de valor. O brilho (luminosidade) corresponde a um valor que equivale a um tom pertencente a uma escala acromática entre o branco (luminosidade máxima) e o preto (luminosidade 
mínima) ao qual a cor corresponde ao se considerar apenas o brilho desconsiderando o matiz. É o tom que a cor assumiria numa versão em preto-e-branco.

Feita essa explanação, à luz de Dondis (2007), importa salientar que o mais emocional dos elementos específicos do processo visual é a percepção da cor. Essa propriedade intensifica a informação visual. A cor tem, não somente, um significado compartilhado universalmente por meio da experiência, mas um significado que se processa nos meandros da cultura.

Ainda que nossas escolhas cotidianas não se deem tão conscientemente, o fato é que revelamos coisas ao mundo sempre que optamos por determinada cor.

Prossigamos na busca da intenção da presidente, a partir de suas escolhas.

\section{A cor na construção dos sentidos das vestimentas}

Nas análises seguintes, buscaremos o potencial de sentidos gerado pela cor vermelha nas roupas usadas pela presidente Dilma nos momentos escolhidos de sua trajetória política.

Figura 1 - Foto oficial da campanha de Dilma Rousseff

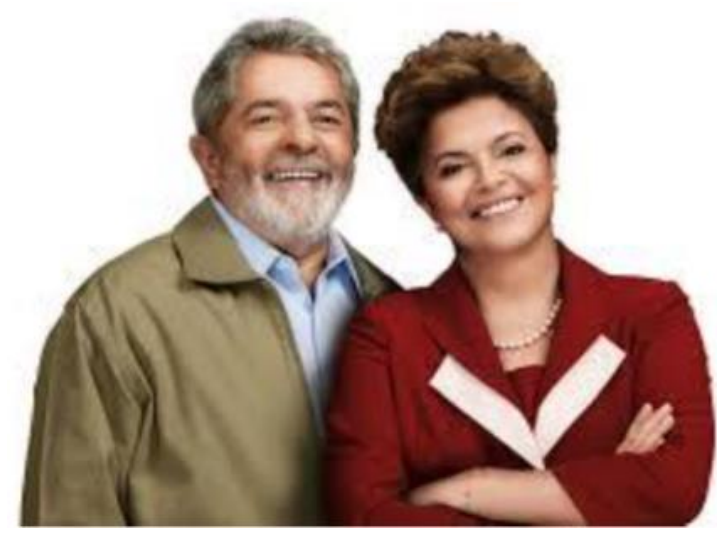

Fonte: Tavares (2014).

A cor vermelha como qualissigno ganha, inicialmente, nosso olhar. Vimos que o vermelho é a mais ativa e emocional das cores, mas nessa 
imagem a mistura ameniza a provocação do vermelho. A cor deixa de expandir por ser menos saturada. Torna-se mais séria, comportada, elegante. A cor branca aparece fazendo um contraponto ao vermelho. 0 branco, como qualidade, reflete todos os raios de luz, a luminosidade pura.

O vermelho e o branco em detalhe se fazem presentes na vestimenta da candidata a presidente nas eleições de 2010. Estando incorporados ao traje, passam a ser existentes, sinsignos, portanto. Na relação com o objeto que representam - o momento em que a candidata Dilma se lança à chapa do PT para a presidência da República - o vermelho passa a apontar para o contexto em que a imagem o insere. O vermelho passa a ser índice.

O contexto para o qual o vermelho aponta traz Dilma Rousseff, na época ministra de Minas e Energia do governo do presidente Luiz Inácio Lula da Silva, ao lado dele em uma foto/propaganda de sua candidatura. Trata-se da foto oficial de candidatura da Dilma para o PT em 2010, a fim de suceder o presidente Lula ao cargo.

Ao escolher as vestes para se apresentar à nação, Dilma usou um blazer com formas predominantemente retas. Esta forma remete à ideia de ordem e controle, em detrimento da modelagem que segue o corpo feminino, curvilíneo, apresentado por Lurie (1997, p. 221). Outro ponto a ser observado sobre o blazer é que o corte alongado traz ares masculinizados, ligados ao tradicional. A ausência do decote, conforme Sabino (2007, p. 17) "mostra recato e vontade de pouco se mostrar; quadrado - suas formas retas diminuem o volume e mostram firmeza". Dilma usa também alguns acessórios, podemos ver o colar e brinco de pérolas. As pérolas, segundo Sabino (2007, p. 487), "sempre estiveram, em algum momento, demonstrando elegância. Pérolas naturais, cultivadas, verdadeiras, falsas, barrocas, entre tantas outras variações são consideradas valores certos".

O presidente Lula, em contrapartida, veste uma camisa social azul claro e um agasalho na cor bege. Para Heller (2013, p. 23), 
O azul claro é a cor que foi mais vezes citada como a cor da simpatia, da harmonia, da amizade e da confiança. Esses são os bons sentimentos, aqueles que só se comprovam em longo prazo, florescendo, em geral, com o passar do tempo e tendo sempre como base a reciprocidade.

Já o bege, remete à calma e passividade. Tais cores demonstram parceria por meio da 'amizade e confiança' depositadas à sua candidata, fazendo-se segundo plano para deixar que Dilma assuma o papel de herdeira do cargo e da cor típica do seu partido. O vermelho carrega a simbologia do PT e de seus ideais.

Figura 2 - Dilma eleita no seu primeiro mandato

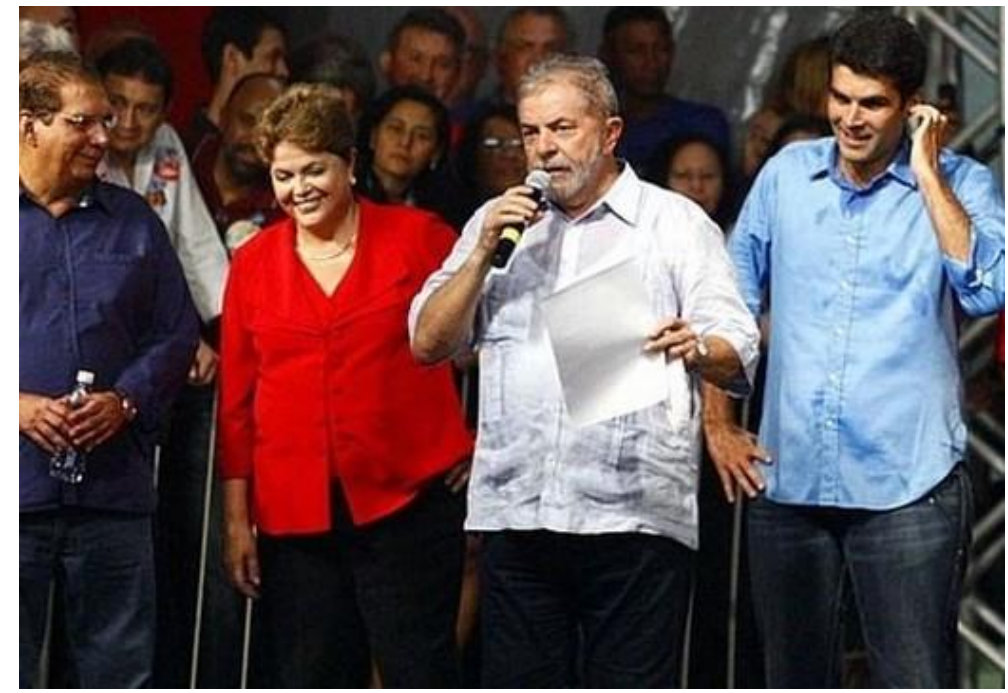

Fonte: Silva (2014).

Um vermelho saturado se destaca entre as cores branca e azul (escuro e claro). Sendo saturada, esta cor se expande, torna-se ponto focal, atrai o olhar para a esquerda da composição.

O vermelho vivo se materializa na camisa da agora presidente eleita Dilma Rousseff. Vermelho e momento festivos. O tecido leve, despojado mantém coerência com a sensação de alívio que o desgaste de uma campanha árdua propicia.

O PT em vermelho vivo grita a vitória. A posição da presidente à esquerda do olhar do intérprete personaliza o partido e acentua sua ideologia. Investe-se, assim, do caráter simbólico, decorrente do 
predomínio do legissigno. Vejamos a simbologia do vermelho nas palavras de Heller (2013, p. 53).

É a mais antiga de todas as cores. O vermelho é a cor de todas as paixões - do amor ao ódio, a cor dos reis e do comunismo, a cor da felicidade e do perigo. É a cor dominante de todas as atitudes positivas em relação à vida, força, da liberdade, dos trabalhadores, do socialismo, das correções, da redução.

No momento político representado pela foto, os valores simbólicos ganham a dimensão conivente com o propósito da escolha da roupa pela presidente. Passemos para o próximo momento da presidente Dilma representativa de seu período de ascensão.

Figura 3 - Ascensão de Dilma Roussef

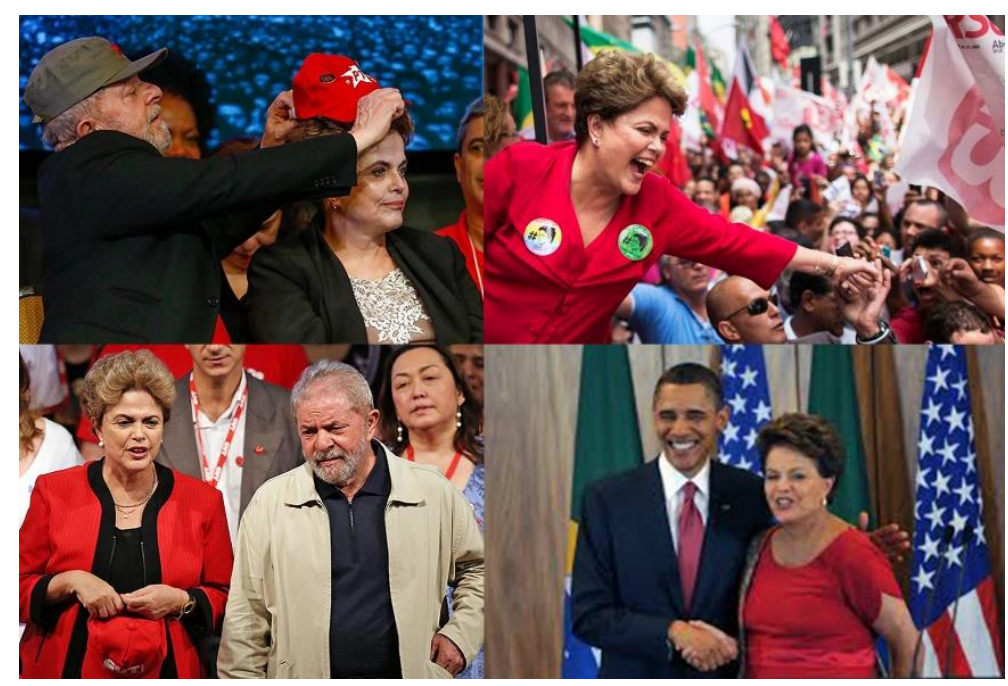

Fonte: Painel composto por imagens do ano 2009 a 2010 disponíveis no acervo online Folha de S.Paulo. Acesso em: 4 jul. 2018.

O vermelho nestas cenas se apresenta saturado nas três primeiras, menos saturado na última. Apresenta-se, respectivamente, ora incorporado num boné; ora na camisa, no casaco. Suas representações simbólicas se dão como pertencimento ao partido e às suas ideologias vislumbradas no ato público de ser "coroada" com o boné do PT; como envolvimento com a massa popular militante; num outro momento em que, usando um casaco mais formal e elegante, dirigido agora a um público mais selecionado, segura na mão o mesmo boné. Em duas das fotografias, o ex-presidente 
Lula se posta ao seu lado, transferindo-Ihe não somente o poder, mas a própria cor característica do partido criado por ele.

A última cena traz um vermelho mais fechado, reservado, menos saturado. Divide espaço com, àquela época, o presidente dos EUA, Barack Obama, homem de grande popularidade e poder.

As quatro imagens distintas têm em comum momentos da ascensão política da presidente Dilma Rousseff. Ao usar o vermelho como base de suas vestes, ela consolida as suas raízes e reforça a sua imagem como presidente guerreira, popular e disposta a comunicar ao mundo sua posição.

Uma pessoa com uma peça vermelha pode inicialmente buscar um estímulo, pretende aumentar a estima ou dissemina uma ideologia centrada em princípios do socialismo, por exemplo. Apesar destes significados, ao escolher um vestido desta cor, a mulher não está construindo apenas uma significância de partidarismo, ela pode disseminar o desejo de sedução, se a veste for construída com formas justas [...] podendo até um boné vermelho remeter aos movimentos sociais. (OLIVEIRA, 2015, p. 21-22).

Figura 4 - O declínio de Dilma

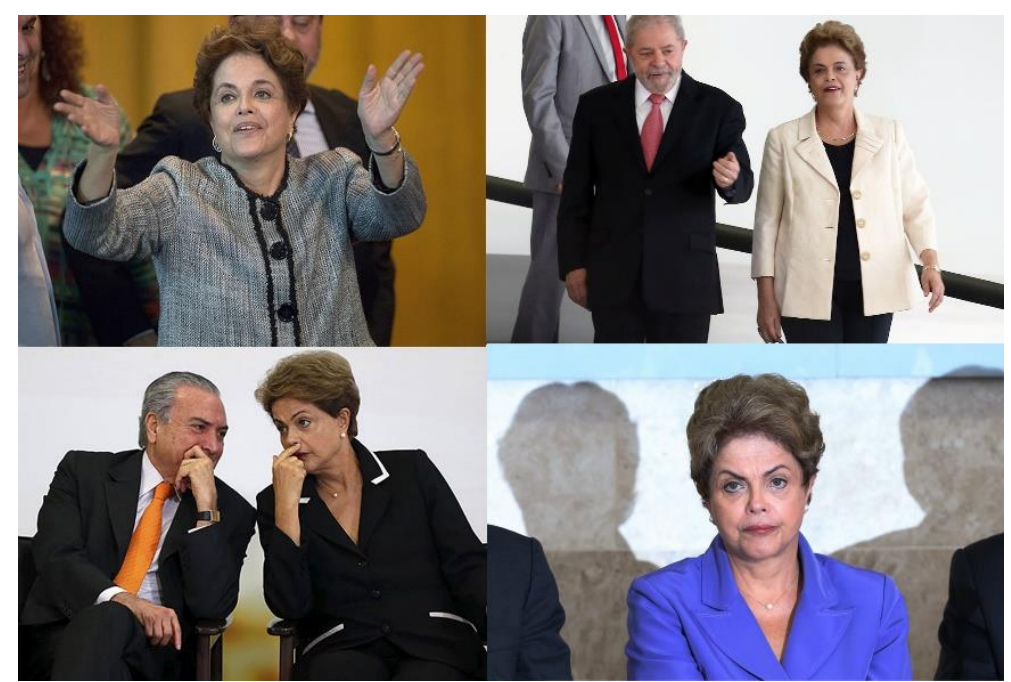

Fonte: Painel composto por imagens do ano 2015 a 2016 disponíveis no acervo online Folha de S.Paulo. Acesso em: 4 jul. 2018.

No painel montado com quatro fotografias da presidente, o vermelho aparece muito timidamente. $O$ jogo do saturado (fundo) com o não saturado (figura) traz equilíbrio, mas são detalhes. 
Trata-se de momentos do segundo mandato da presidente Dilma Rousseff, entre 2015 a 2016. A ausência do vermelho em suas vestimentas é significativa. Tal "silêncio" é revelador do afastamento, da crise; é perceptível na fisionomia fechada, triste, sem brilho. Não por acaso, o que imperou nesse período do segundo mandato foram manifestações constantes decorrentes da insatisfação do povo com o que se denominou "estelionato eleitoral", ou seja, as maquiagens eleitoreiras estavam se fazendo visíveis, o que impulsionou e, mais tarde, concretizou o impeachment da ex-presidente.

O vermelho deixou de ser a marca das vestimentas da presidente desde a campanha para a segunda eleição. A intenção era se afastar das denúncias que atingiam o partido e tonar-se mais próxima dos "outros" brasileiros.

Nota-se nas roupas com que Dilma se veste nas fotos acima a neutralização do preto, branco, cinza e azul que ganha destaque na vestimenta da presidente. Com esta intenção, é possível perceber seu desejo de desvincular sua imagem da dos condenados, ao não optar pelo uso da cor partidária.

A mudança do vermelho para outras tonalidades leva-nos aos sentidos de cada cor. Na esteira de Heller (2013), do vermelho de uma nova ideologia, para o azul da fidelidade; o vermelho da cor da felicidade, para o preto da ambivalência dos sentidos. O vermelho do amor e ódio, para o branco da ressurreição, do bem e da perfeição. O vermelho do início, do sangue e da vida, para o cinza do secreto, do passado e esquecimento. Apesar desse afastamento do vermelho, Dilma continua com as formas retas do blazer, afastando a fragilidade/feminilidade na sua imagem, mantendo os ares de ordem e o controle em cada nova aparição; escolhas estas que propagam a ideia de coragem para enfrentar qualquer adversidade. 
Figura 5 - A "queda" de Dilma

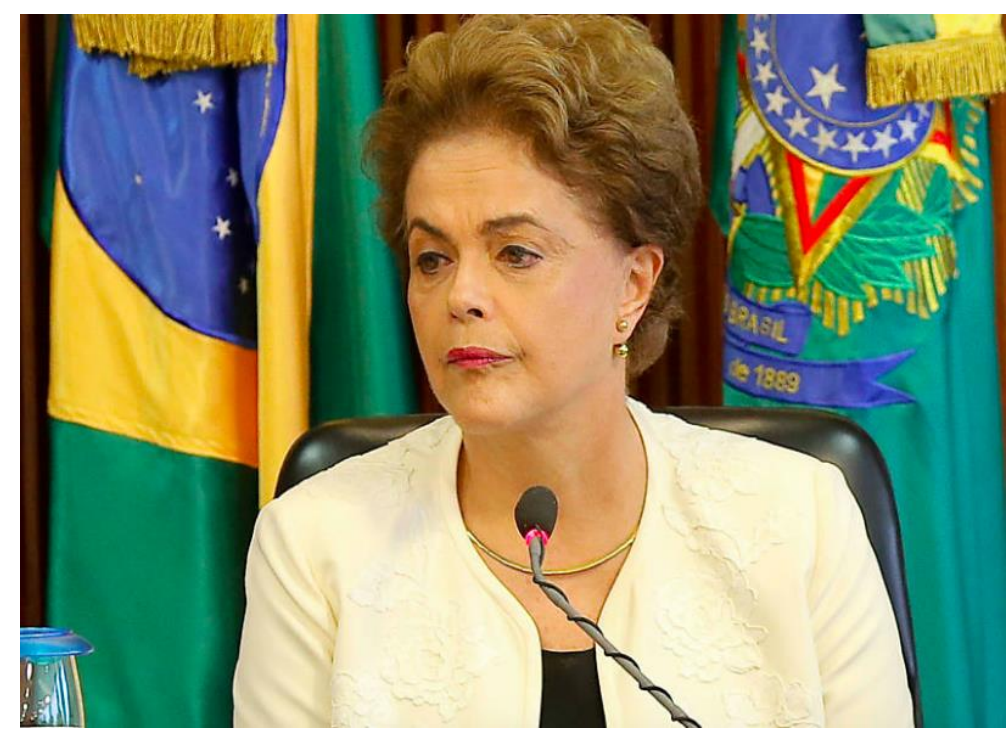

Fonte: Falção (2016).

A Figura 5 é representativa da queda da presidente Dilma Rousseff no impeachment ocorrido no final de 2016.

O vermelho novamente silencia. Silencia também seu partido, sua ideologia, suas promessas. Aqui é substituído pelo bege e preto. O blazer estruturado também é substituído por linhas curvas e mais leves, além de conter um bordado de flores na mesma cor da peça. Outra substituição foram os acessórios feitos em pérola para correntes e brincos dourados.

Nesta nova fase, a predominância das cores neutras em sua vestimenta demonstra a centralização dos seus objetivos (HELLER, 2013). A modelagem da sua vestimenta mais simples, indicia sua proximidade com seu público. O blazer menos estruturado, substituindo linhas retas por linhas curvas, sugere liberdade e descontração, conforme Lurie (1997, p. 221), intensifica a feminilidade também por conta dos bordados, finos e discretos. Já a ambiguidade das cores na combinação do bege e preto remete à calma e passividade e, ao mesmo tempo, conforme Heller (2013), sugere o fim, poder, negação e elegância, duro e pesado.

Quanto aos acessórios, Dilma persiste nos usos de acessórios discretos, apenas substituindo a pérola por brincos e correntes dourados. Sabino (2007) e O'Hara (1992) defendem que no dourado do ouro 
transparece o valioso, a riqueza, a fortuna, remetendo às ideias sólidas e qualidades morais.

Com estes valores, a ex-presidente, talvez, buscasse sair de cena com dignidade.

\section{Considerações finais}

Neste artigo, depositamos no vermelho nosso olhar, buscando desvelar seus aspectos qualitativos, existentes e simbólicos na produção de sentidos das vestimentas da ex-presidente do Brasil, Dilma Rousseff.

Atrelada a diferentes momentos da carreira política de Dilma Rousseff, no período que antecedeu sua primeira eleição até seu impeachment, a cor vermelha perpassou seu pertencimento ao Partido dos Trabalhadores; sua identificação com a ideologia do PT e sua ascensão na política. O padrão e repetição do vermelho nas escolhas da sua vestimenta constroem sua imagem de forma sólida, desenvolvendo-a em conjunto com a cor do seu partido.

Porém, já na campanha eleitoral para o segundo mandato, fatos que comprometiam o partido vieram à tona, provocando a indignação da população. O afastamento do vermelho é significativo, pois insistir em sua ideologia, em seu significado simbólico seria estar conivente com os fatos comprometedores da sua moral. O vermelho se intensifica em valor, tornando-se, neste período, a representação da desonestidade, da fraude, da inconfiabilidade.

Também é perceptível que, ao escolher durante grande parte do seu mandato modelagens alongadas com linhas retas e estruturadas, a presidente mostra um pertencimento ao universo político, marcado pelo viés masculino e tradicional próprios desse território. Aliados à ideia de masculinidade estão sentidos tais como coragem, poder de decisão, mas ao trazer o uso do decote ou gola no formato redondo, comum nas últimas vestimentas e caimento mais leve, a ideia de elegância e feminilidade se 
sobrepõe à anterior. Tais escolhas a distanciavam da imagem antiga, de uma mulher intocável.

Assim, pudemos perceber na análise da cor vermelha, em seus níveis - quali, sin e legissigno - que seguem as categorias peircianas primeiridade, secundidade e terceiridade - a qualidade da cor nos atributos que a distinguem das outras e a tornam prenhe de sentidos; a cor como um existente que se encarna na vestimenta de uma figura política da maior importância no país e aponta para o contexto em que se fez presente, bem como sua ausência; finalmente, nas construções simbólicas que vêm agregar significados ideológicos que extrapolam os anteriores, significados atrelados a padrões culturais, sociológicas; à história.

Vermelho/vestimenta se apresentaram inscritos na interface Comunicação/Moda como produtores de sentidos capazes de desvelar a construção da imagem da presidente Dilma no período recortado para este artigo.

\section{Referências}

BARNARD, Malcolm. Moda e comunicação. Rio de Janeiro: Rocco, 2003. CUNHA, Isabel Maria Ribeiro Ferin. Dilma Rousseff da ditadura militar ao facebook: a construção da imagem do indivíduo na política. $2014.154 \mathrm{f}$. Dissertação (Mestrado em Comunicação e Jornalismo) - Departamento de Filosofia, Comunicação e Informação da Faculdade de Letras, Universidade de Coimbra, Coimbra, 2014.

DONDIS, Donis A. A sintaxe da linguagem visual. São Paulo: Martins Fontes, 2007.

FALÇÃO, Márcio. Duas visões juristas contra e favor avaliam pedido de impeachment. Folha de S. Paulo, São Paulo, 18 mar. 2016. Online. Disponível em: https://www1.folha.uol.com.br/poder/2017/02/1256272-duas-visoesjuristas-contra-e-a-favor-avaliam-pedido-deimpeachment,a67e5b1d8785cd72e7656fac0563d5339d1vy88p.html. Acesso em 4 jul. 2018.

HELLER, Eva. A psicologia das cores. São Paulo: Gustavo Gili, 2013. LURIE, Alison. A linguagem das roupas. Rio de Janeiro: Rocco, 1997. O'HARA, Georgina. Enciclopédia da moda: de 1840 à década de 80 . São Paulo: Companhia das Letras, 1992. 
OLIVEIRA, Karla Beatriz Barbosa de. A roupa da Presidente: uma análise de comunicação pelas vestes. 2015. $81 \mathrm{f}$. Monografia (Projeto Final em Jornalismo) - Faculdade de Comunicação, Universidade de Brasília, Brasília, 2015.

QUEIROZ, Adolpho; MARTINS Jr., Francisco Ramirez. Presidente Dilma, com que roupa eu vou? Compolítica, Rio de Janeiro, n. 1, vol. 1, mar./abr. 2011.

SABINO, Marco. Dicionário da moda. Rio de Janeiro: Elsevier, 2007.

SANTAELLA, Lucia. Semiótica aplicada. São Paulo: Pioneira Thomson Learning, 2005.

SILVA, Reinaldo. Folha de S. Paulo. São Paulo, 25 out. 2014. Online. Disponível em: Acesso em: 3 jul. 2018.

TAVARES, Luciano. A campanha de Dilma Rousseff em 10 fotos. Folha de $\mathbf{S}$. Paulo, São Paulo, 25 out. 2014. Online. Disponível em:

https://fotografia.folha.uol.com.br/galerias/29843-a-campanha-de-dilmarousseff-em-10-fotos. Acesso em 3 jul. 2018. 